\title{
NÍVEIS DE SUPERÓXIDO DISMUTASE PRODUZIDOS POR MONÓCITOS EM PORTADORES DE ESQUISTOSSOMOSE HEPATOESPLÊNICA SUBMETIDOS A ESPLENECTOMIA, LIGADURA DA VEIA GÁSTRICA ESQUERDA E AUTO- IMPLANTE DE TECIDO ESPLÊNICO NOOMENTOMAIOR
}

\author{
SUPEROXIDE DISMUTASE MONOCYTE PRODUCTION LEVELS IN PATIENTS WITH \\ HEPATOSPLENIC FORM OF SCHISTOSOMA MANSONI INFECTION, WHO UNDERWENT \\ SPLENECTOMY, LEFT GASTRIC VEIN LIGATURE AND SPLEEN TISSUE \\ AUTOIMPLANTATION ON THE GREATER OMENTUM
}

\author{
Carlos Teixeira Brandt, TCBC-PE ${ }^{1}$; Carlos Roberto Carvalho Leite, ACBC-PE ${ }^{2}$; \\ Francisco Machado Manhaes-de-Castro ${ }^{3}$; Érika Michelle Correia de Macedo ${ }^{3}$; \\ Rebecca Peixoto Paes Silva ${ }^{3}$; Célia Maria Machado Barbosa de Castro ${ }^{4}$
}

\begin{abstract}
RESUMO: Objetivo: Investigar os níveis de produção de SOD por monócitos periféricos em pacientes jovens portadores de esquistossomose hepatoesplênica submetidos à esplenectomia, ligadura da veia gástrica esquerda e auto-implante de tecido esplênico. Método: Quatro grupos foram envolvidos na investigação: G1 - 12 portadores de esquistossomose hepatoesplênica (EHE) sem tratamento; G2 - 13 portadores de EHE que receberam tratamento clínico e se submeteram à operação para descompressão do sistema porta: esplenectomia e ligadura da veia gástrica esquerda (EHE/ELGE); G3 - 19 pacientes jovens similares a G2, mas que receberam também auto-implante de tecido esplênico no omento maior (EHE/ELGE/AI); e G4 - 15 indivíduos sem infecção pelo $S$. mansoni advindos da mesma área geográfica, apresentando as mesmas condições sócio-econômicas (GC). Resultados: Os indivíduos normais (GC - sem esquistossomose) apresentam níveis de SOD significantemente menores que os portadores de EHE sem tratamento ( $\mathrm{p}<0,01)$; e aqueles do grupo EHE/ELGE ( $<<0,05)$. Os níveis de SOD do grupo EHE/ ELGE/AI são estatisticamente similares ao grupo GC (p>0,05). Conclusão: Os resultados corroboram a hipótese de que o tratamento clínico associado à esplenectomia, ligadura da veia gástrica esquerda e auto-implante de tecido esplênico, em portadores jovens de esquistossomose hepatoesplênica, tendem a manter a resposta imune desses indivíduos (Rev. Col. Bras. Cir. 2007; 34(1): 25-30).
\end{abstract}

Descritores: Esquistossomose mansoni; Baço; Esplenectomia; Superóxido dismutase; Auto-imunidade.

\section{INTRODUÇÃO}

A esquistossomose é uma doença que afeta mais de 200 milhões de africanos, asiáticos e americanos e sendo considerada como problema de Saúde Públicaํ. No Brasil, houve sucesso na redução das formas graves, entretanto, o mesmo não aconteceu na interrupção da transmissão, e nem na redução da prevalência com nível inferior a 5\%. Na região Nordeste concentram-se as prevalências mais elevadas ${ }^{2}$.

Com relação à infecção por Schistosoma mansoni em Pernambuco podemos afirmar que o número de hospitalizações nessas regiões diminuiu no período de 1995 a 1998, e aumentou no período de 1999 a $2000^{3}$. Nesse Estado, o tratamento cirúrgico para hipertensão porta inclui esplenectomia e ligadura da veia gástrica esquerda ${ }^{4}$; em crianças o auto-implante de tecido esplênico no omento maior é adicionado para prevenção de infecção fulminante pós esplenectomia ${ }^{5}$. O risco de infecção grave é um problema importante em pacientes esplenectomizados ${ }^{6}$.

O efeito imune de proteção da esplenose após autoimplante de tecido esplênico no omento maior em crianças portadoras de esquistossomose mansônica que se submeteram a esplenectomia tem sido estudado. Todavia, embora vários estudos ${ }^{5,7,8}$ emprestem suporte ao conceito da manutenção da função imune esplênica após esse procedimento, o assunto ainda é objeto de controvérsia quando os monócitos desses pacientes são submetidos ao stress ${ }^{8}$.

Um aspecto importante após os tratamentos clínico e cirúrgico dos portadores de esquistossomose hepatoesplênica é a possibilidade de nova infecção. Nesse sentido a manutenção dos pacientes nas áreas endêmicas torna possível esse fato. Além do mais, aproximadamente um

1. Professor Titular de Clínica Pediátrica Cirúrgica, CCS, UFPE.

2. Mestre em Cirurgia, CCS, UFPE.

3. Bolsista de Iniciação Científica - CNPq

4. Professor Adjunto em Medicina Tropical, CCS, UFPE.

Recebido em 14/02/06

Aceito para publicação em 15/08/06

Conflito de interesses: nenhum

Fonte de financiamento: nenhuma

Trabalho realizado no Serviço de Cirurgia Pediátrica do Hospital das Clínicas do Centro de Ciências da Saúde e no Laboratório de Imunologia Keijo Assami (LIKA) - Universidade Federal de Pernambuco. 
em cada cinco dos pacientes jovens tratados mantém carga parasitária residual após os tratamentos clínico e cirúrgico, o que pode continuar repercutindo na reserva funcional hepática desses pacientes ${ }^{9}$.

A associação entre os níveis hepáticos de superóxido dismutase (SOD) e infecção por $S$. mansoni tem sido demonstrada em camundongos. Esses animais quando infectados apresentam altos níveis dessa enzima, que retornam a valores normais quando recebem tratamento com praziquantel ${ }^{10}$. Por outro lado, como parte da resposta citotóxica do ser humano contra a infecção por S. mansoni, sobretudo na forma de larva, está a produção de radicais oxidantes como o anion superóxido e hidroxilas ${ }^{11}$. Entre os mecanismos de sobrevivência dos parasitas na relação parasita hospedeiro, encontra-se a produção de enzimas antioxidantes como a $\mathrm{SOD}^{11-13}$.

O stress oxidativo tem papel importante no sistema de defesa imune dos seres humanos, todavia os níveis dos agentes oxidantes são controlados pelo sistema de defesa anti-oxidante, o qual é composto por anti-oxidantes e proanti-oxidantes ${ }^{14}$. Pacientes com colestase crônica, particularmente aqueles com cirrose, são mais susceptíveis às complicações infecciosas, apresentando acentuada diminuição do status anti-oxidante tanto no soro como nos neutrófilos ${ }^{15}$. De forma similar, as crianças com desnutrição grave apresentam significante diminuição da atividade da SOD, quando comparado com crianças normais ${ }^{16}$.

Sendo a esquistossomose mansônica na forma hepatoesplênica uma doença que, de certa forma, compromete a reserva funcional hepática, e levando em consideração que o tratamento cirúrgico da hipertensão porta no Nordeste do Brasil inclui a esplenectomia, com conseqüente aumento do risco de infecção, esse estudo teve como objetivo avaliar os níveis de SOD produzido por células mononucleares do sangue periférico de adolescentes e adultos jovens portadores de esquistossomose na forma hepatoesplênica, que tinham se submetido, quando crianças, à esplenectomia, ligadura da veia gástrica esquerda e auto-implante de tecido esplênico, em bolsa, no omento maior.

\section{MÉTODO}

O estudo foi prospectivo, realizado no Serviço de Cirurgia Pediátrica do Hospital das Clínicas do Centro de Ciências da Saúde e no Laboratório de Imunologia Keijo Assami (LIKA) - Universidade Federal de Pernambuco. pesquisa:

Foram constituídos quatro grupos de voluntários da

G1 - 12 portadores da infecção por S. mansoni na forma hepatoesplênica sem ter recebido nenhuma forma de tratamento (Grupo clínico de referência - EHE). Dez eram mulheres e dois homens. As idades variaram de 10 a 30 anos (Média $=20,0 \pm 2,1$ anos). Todos os pacientes eram provenientes de área endêmica para infecção por $S$. mansoni. Todos apresentavam Kato-Katz positivo.

G2 - 13 pacientes EHE, semelhantes aos do G1, mas, apresentavam antecedentes de hemorragia digestiva alta por varizes de esôfago, comprovadas por endoscopia digestiva alta. Nove eram mulheres e quatro eram homens. As idades variavam de 18 a 30 anos (Média $=24,6 \pm 3,4$ anos). Eles tinham recebido tratamento clínico com praziquantel $(20 \mathrm{mg} / \mathrm{Kg})$ em dose única, e se submetido à esplenectomia e ligadura da veia gástrica esquerda, para descompressão do sistema porta. (Grupo cirúrgico de referência - EHE/ELGE).

G3 - 19 pacientes jovens clinicamente similares aos do grupo G2. Treze eram mulheres e seis homens. As idades variaram de 16 a 25 anos (Média $=20,2 \pm 3,6$ anos). Todos receberam tratamento médico pré-operatório com uma dose única de oxaminiquine $20 \mathrm{mg} / \mathrm{Kg}$. Eles se submeteram à esplenectomia, ligadura da veia gástrica esquerda e auto-implante de dez fragmentos sem cápsula, do polo superior do baço, envelopados em uma bolsa no omento maior. As medidas e os pesos desses fragmentos foram aproximadamente: $3 \times 2 \times 2 \mathrm{~cm}$ ( $\pm 10 \mathrm{~g}$ cada). Todos tiveram comprovação de pega satisfatória dos implantes, avaliada por medicina nuclear usando cintilografia com enxofre coloidal marcado com Tecnécio99. (Grupo Estudo - EHE/ ELGE/AI) $)^{5}$.

O seguimento clínico e laboratorial desses pacientes é feito a cada seis meses ou quando ocorre alguma alteração clínica, como, por exemplo, sangramento digestivo alto. A endoscopia digestiva alta é realizada a cada seis meses para avaliação das varizes de esôfago e da gastropatia. Os pacientes que apresentaram recidiva de hemorragia digestiva alta foram incluídos no protocolo de esclerose endoscópica das varizes de esôfago.

A colonoscopia é realizada anualmente no seguimento pós-operatório, o qual, neste grupo é de cerca de sete anos. Esse procedimento é feito não apenas para seguimento da colopatia, mas também para avaliação da infecção residual pelo $S$. mansoni pelo oograma quantitativo de rotina. São utilizados três biopsias de submucosa no reto, sigmóide e cólon descendente.

A investigação laboratorial nesse grupo incluiu, entre outros exames, a avaliação da reserva funcional hepática. Antes dos tratamentos médico e cirúrgico 14 (73,7\%) pacientes foram classificados como Child-Pugh A e 5 (26,3\%) foram Child-Pugh B. No ultimo seguimento pós-operatório $17(89,5 \%)$ pacientes foram Child-Pugh Ae $2(10,5 \%)$ foram Child-Pugh B.

G4 - 15 indivíduos sem infecção por S. mansoni, que viviam na mesma área e apresentavam as mesmas condições sócio-econômicas dos pacientes incluídos nos grupos G1, G2 e G3. Oito eram mulheres e sete homens. As idades variaram de 15 a 28 anos (Média = 19,3 \pm 4,3 anos) - (Grupo Controle GC).

Todos os pacientes foram cuidados no Hospital das Clínicas do Centro de Ciências da Saúde da Universidade Federal de Pernambuco.

A obtenção de monócitos no sangue periférico (PBMC) foi realizada segundo o protocolo descrito a seguir: sangue obtido era distribuído em tubo estéril, de vidro, com capacidade para $50 \mathrm{ml}$; posteriormente, diluído na proporção de 1:2 em meio de cultura Roswell Park Memorial Institute (RPMI 1640), estéril a $8^{\circ} \mathrm{C}$. Aos $40 \mathrm{ml}$ da suspensão 
eram adicionados $10 \mathrm{ml}$ de Histopaque (SIGMA). A mistura era centrifugada por 30 minutos a $1400 \mathrm{rpm}\left(2^{\circ}\right.$ a $\left.8^{\circ} \mathrm{C}\right)$. A seguir, era coletada, com pipeta de Pauster, a camada formada pelas células mononucleares do sangue periférico (PBMC), que era transferida para outro tubo de centrífuga. Na seqüência eram adicionados $15 \mathrm{ml}$ de meio RPMI 1640, e feita nova centrifugação por 10 minutos nas mesmas condições anteriores. O sobrenadante era aspirado e desprezado. Posteriormente, o sedimento era ressuspendido em $2 \mathrm{ml}$ de meio de cultura RPMI 1640 completo, contendo soro fetal bovino a $3 \%$ e antibióticos (penicilina 100U/ml e estreptomicina $100 \mathrm{mg} / \mathrm{ml}$ ). Desta última solução, era retirada alíquota de $10 \mathrm{ml}$ e colocada em tubo Eppendorf, plástico e estéril, e adicionado, à suspensão de células, $90 \mathrm{ml}$ do corante azul tripan a $0,05 \%$. Ao final, a mistura era disposta sobre uma lâmina espessa de vidro (Hemocitômetro ou Câmara de Neubauer), a qual era levada ao microscópio óptico para contagem das células.

A atividade da superóxido dismutase (SOD) foi mensurada pelo método da quimioiluminescência ${ }^{17}$. O superóxido era gerado pelo sistema xantina/xantina oxidase. Os monócitos $\left(10^{6}\right)$ aderidos á placa de cultura eram estimulados com acetato miristato de forbol (PMA) e sonicados para análise da atividade da SOD. O ensaio da quimioiluminescência era realizado em $0,1 \mathrm{M}$ de glicina em $\mathrm{NaOH}, \mathrm{pH}$ de 9,0 , contendo $1 \mathrm{mM}$ de EDTA e $1 \mathrm{mM}$ de salicilato sódico. A reação era iniciada pela adição de $0,2 \mathrm{ml}$ de solução de xantina em uma concentração final de 2,5 x $10^{-5} \mathrm{M}$ para $0,2 \mathrm{ml}$ de xantina oxidase (concentração final de $4 \mathrm{mU} / \mathrm{amostra}$ ), na presença de lucigenina (concentração final de $0,1 \mathrm{mM}$. A intensidade da luz era mensurada 30 segundos após iniciada a reação pela xantina. Quantidades de SOD nas amostras eram calculadas pela comparação do seu efeito inibitório na formação do superóxido com o efeito de aumento conhecido de concentração de SOD purificada, usando SOD inativada pelo calor como $0 \%$ de inibição. As mensurações eram realizadas antes e após estimulação, quando o pico da quimioiluminescência dependente da lucigenina era alcançado. Foi realizada uma curva cinética da atividade da enzima nos tempos $0,5,10$ e 15 minutos. Como o tempo de 10 minutos foi o de maior atividade em todos os grupos, e o que apresentou menor grau de dispersão dos resultados, foi tomado como tempo de leitura. Os resultados da leitura foram expressos em ng SOD/mg de proteína.

Utilizou-se o teste de comparação múltipla de TukeyKramer para verificação de diferenças entre as médias dos valores de SOD nos grupos envolvidos no estudo; sendo aceito $\mathrm{P}<0,05$ para rejeição da hipótese de nulidade.

O estudo faz parte de uma linha de pesquisa do programa de pós-graduação em cirurgia do Centro de Ciências da Saúde da Universidade Federal de Pernambuco, cujo projeto foi aprovado pelo Comitê de Ética da Instituição.

\section{RESULTADOS}

As médias dos níveis de SOD produzidos por monócitos dos quatro grupos envolvidos na investigação estão expressos na Tabela 1.

\section{DISCUSSÃO}

Existem várias ações visando o controle da esquistossomose, incluindo medidas contra os hospedeiros intermediários; melhora das condições higiênica e sanitária da população exposta, assim como melhora do suprimento de água potável; melhora da educação sanitária desta população; tratamento intensivo, individual ou coletivo das pessoas nas áreas de alta prevalência; proteção contra a penetração das cercarias de $S$. mansoni; e vacina que venha a proteger estes indivíduos expostos ${ }^{2}$. Todavia, os obstáculos são importantes e requerem decisão política e investimentos públi-

Tabela 1 - Média dos níveis de SOD (ng SOD/mg de proteína) produzidos por monócitos do sangue periférico dos quatro grupos.

\section{Grupos:EHE;EHE/ELGE;EHE/ELGE/AI;eGC}

Portadores de esquistossomose na forma hepatoesplênica (EHE)

Pacientes esplenectomizados (EHE/ELGE)

Pacientes esplenectomizados com auto-implante (EHE/ELGE/AI)

Grupo controle (GC)

Teste de comparação múltipla de Tukey-Kramer

\begin{tabular}{|c|c|c|c|}
\hline Comparações & Diferenças de médias & $\mathbf{q}$ & $\mathbf{P}$ \\
\hline GC versus EHE/ELGE/AI & 2,17 & 2,71 & $P>0,05$ \\
\hline GC versus EHE/ELGE & 3,35 & 3,76 & $\mathrm{P}<\mathbf{0 , 0 5}$ \\
\hline GC versus EHE & 4,15 & 7,29 & $\mathbf{P}<\mathbf{0 , 0 1}$ \\
\hline EHE/ELGE/AI versus EHE/ELGE & 1,19 & 4,41 & $\mathrm{P}>0,05$ \\
\hline EHE/ELGE/AI versus EHE & 1,98 & 4,98 & $P>0,05$ \\
\hline EHE/ELGE versus EHE & 0,79 & 0,89 & $P>0,05$ \\
\hline
\end{tabular}


cos, não disponíveis ${ }^{2,12,18,19}$. É importante ser assinalado que todos os voluntários da investigação vivem na Região da Mata de Pernambuco, onde a maioria da população tem baixo poder aquisitivo e apresenta baixo nível de educação. Além do mais, homens e mulheres desenvolvem atividades de subsistência, como pesca e lavagem de roupa, nos rios infestados pelo hospedeiro intermediário e pelos $S$. mansoni.

Educação básica para todos os indivíduos do Nordeste do Brasil, poderia ser o início da solução deste problema de saúde pública que ainda acomete vários estados, incluindo Pernambuco $^{3}$. Uma melhor distribuição econômica poderia se constituir na conseqüência lógica. Essas ações seriam importantes no controle mundial desta doença, ainda prevalente em vários paises ${ }^{20}$, incluindo o Brasil ${ }^{1}$.

A patogênese desta doença na forma hepatoesplênica resulta dos ovos produzidos por S. mansoni adultos que habitam a circulação porta de seres humanos. A gravidade da doença é uma função da carga parasitária e, conseqüentemente, da reposta inflamatória do hospedeiro aos ovos depositados nos espaços porta do fígado. Assim sendo, aproximadamente $10 \%$ dos indivíduos infectados apresentam as formas mais graves, incluindo a hepatoesplênica com hipertensão porta, varizes esofagianas e sangramento digestivo alto.

A utilização de enzimas que atuam no metabolismo de radicais oxidantes livres, tanto pelos parasitas, quanto pelos hospedeiros constitui-se em uma arma poderosa na tentativa de evasão dos hóspedes do sistema porta, assim como das células mononucleares componentes do sistema de defesa do ser humano. Além do mais, o uso de vacina baseada em antioxidantes, como a super óxido dismutase (SOD), contra vermes adultos de S. mansoni constitui objeto de investigação recente, com resultados promissores $^{12}$.

Deve-se ressaltar que os radicais oxidantes livres, como os anions superóxido, representam papel importante na mediação do processo de infecção, por interferirem, em associação com interleucinas, na aderência das células mononucleares e nas bactérias, - processo envolvido tanto pelos agentes infecciosos quanto pelo sistema de defesa dos seres humanos ${ }^{21}$. Além do mais, ele faz parte do stress oxidativo, que é importante fator na tentativa de equilíbrio infecção - resposta imune. A SOD, por outro lado, é importante como catalisador da atividade de dismutação desse anion, regulando a otimização e a limitação de sua ação, que tanto pode ser benéfica para o organismo como pode vir a ser danosa para um conjunto de células do hospedeiro ${ }^{13}$. Assim sendo, manter níveis adequados de SOD é importante, do ponto de vista da regulação, tanto no mecanismo de preservação e defesa do hospedeiro, como no estabelecimento de mecanismo que vise impedir uma nova infecção pelo $S$. mansoni, pois essa enzima é, sobretudo, importante contra as formas de larva desse parasita ${ }^{14}$.

$\mathrm{O}$ fato dos portadores de esquistossomose mansônica na forma hepatoesplenica apresentarem os níveis mais elevados de SOD, nos monócitos periféricos, está em consonância com trabalho experimental em camundongos portadores da mesma doença, onde foi observado que os níveis elevados de SOD hepática eram normalizados quando tratados com praziquantel ${ }^{10}$. Estas altas concentrações de SOD nos pacientes sem tratamento interferem na desativação de radicais oxidantes livres que poderiam ser ativados na eliminação de novas larvas do $S$. mansoni, diminuindo a resistência desses indivíduos a novas infecções ${ }^{22}$.

De forma similar, o achado de níveis de SOD nos pacientes do grupo EHE/ELGE/AI próximos aos dos indivíduos do grupo controle sugere que esses pacientes receberam tratamento clínico adequado. Vale ressaltar que neste grupo os pacientes são submetidos a colonoscopia anualmente, não apenas para controle da colopatia esquistossomótica, assim como para avaliação, pelo oograma quantitativo, de carga parasitária residual. Assim sendo, os cinco dos dezenove pacientes deste grupo que apresentavam ou carga parasitária residual, ou tinham sofrido nova infecção, receberam um segundo tratamento com praziquantel, o que deve ter contribuído para melhor erradicação da parasitose, que conseqüentemente contribuiria para melhor estabilização dos níveis de SOD. Há que se observar que os pacientes que apresentam carga parasitária residual têm uma tendência a apresentar menor reserva funcional hepática ${ }^{9}$, tornando-os susceptíveis do ponto de vista da resposta imune a infecções ou infestações parasitárias. Levando em consideração que a colonoscopia não é feita de rotina nos adultos do grupo EHE/ELGE é provável que alguns pacientes ainda tenham doença em atividade, o que poderia estar associado a níveis mais altos de SOD; próximos aos pacientes não tratados.

Por outro lado, deve ser ressaltado que a diminuição do sistema de defesa antioxidante, pode levar ao excesso na formação de radicais livres que pode promover ou intensificar o processo da patogênese da doença hepática, fato que ocorre em portadores de doenças crônicas desse orgão ${ }^{15}$, podendo, de forma similar, ocorrer em portadores da forma hepatoesplênica da esquistossomose mansônica. Além do mais, a diminuição de SOD também pode ocorrer em portadores de desnutrição ${ }^{16}$, condição encontrada com certa freqüência nos portadores de esquistossomose mansônica na forma hepatoesplênica residentes na região da mata do estado de Pernambuco, de onde provêm todos os envolvidos na investigação. Estas observações emprestam suporte a hipótese de que a falta de homeostase dos radicais livres pode contribuir para o desenvolvimento do dano no espaço porta em portadores da forma hepatoesplênica da infecção pelo $S$. mansoni.

Os resultados evidenciando a similaridade das concentrações de SOD produzida por monócitos de indivíduos normais com a produzida pelos portadores jovens de esquistossomose hepatoesplênica emprestam suporte adicional à hipótese de que o tratamento clínico, e a esplenectomia, ligadura da veia gástrica esquerda e o autoimplante de tecido esplênico, nestes pacientes, tendem a manter sua resposta imune. Os pacientes jovens portadores de esquistossomose tendem a manter sua resposta imune após o tratamento operatório. 


\begin{abstract}
Background: Super oxide dismutase (SOD) is an enzyme that catalyzes the dismutation of super oxide radicals. It is important not only for protecting the human immune system against $\mathrm{S}$. mansoni, as well as for producing competent response from the host against this parasite or other infectious agents. So, it has been investigated the production levels of SOD by peripheral monocytes from young carriers with hepatosplenic schistosomiasis mansoni who underwent splenectomy, left gastric vein ligature and spleen tissue autoimplantation. Methods: Four groups were enrolled in the investigation: G1 - 12 carriers with hepatosplenic schistosomiasis mansoni without treatment (HSM); G2 - 13 HSM patients who received medical treatment and underwent surgery for relief of portal hypertension - splenectomy and left gastric vein ligature (HSM/SLGV); G3 - 19 young patients, similar to those of G3 who in addition received spleen morsels autoimplantation on the greater omentum (HSM/SLGV/AI); and G4 - 15 subjects from the same area with the same economical status without $\mathrm{S}$. mansoni infection (Control group CG). Results: The CG presented significantly lower levels of SOD as compared with the HSM patients ( $p<0.01)$ and those of G2 (HSM/SLGV) - $(p<0.05)$. Levels of SOD from patients of group G3 (HSM/SLGV/AI) were similar to those of the control group $(p>0.05)$. Conclusion: The results lend further support to the hypothesis that clinical treatment followed by splenectomy, left gastric vein ligature and spleen morsels autoimplantation in young patients, who were schistosomiasis mansoni carriers with hepatosplenic form, helps to maintain the immune response of these patients.
\end{abstract}

Key words: Schistosomiasis mansoni; Spleen; Splenectomy; Superoxide dismutase; Autoimmunity.

\section{REFERÊNCIAS}

1. WHO. World Health Organization (1993b). The control of schistosomiasis. Report of the WHO Expert Committee. Geneva: WHO (Technical Report Series, 830; 1-86).

2. Coura JR, Amaral RS. Epidemiological and control aspects of schistosomiasis in Brazilian endemic areas. Mem Inst Oswaldo Cruz. 2004;99(5 Suppl 1):13-9. Epub 2004 Oct 13.

3. Resendes APC, Souza-Santos R, Barbosa CS. Internação hospitalar e mortalidade por esquistossomose mansônica no Estado de Pernambuco, Brasil, 1992/2000. Cad Saúde Pública. 2005;21(5):1392-401.

4. Ferraz AAB, Lopes EPA, Barros FMR, Sette MJA, Arruda SMB, Ferraz EM. Esplenectomia com ligadura da veia gástrica esquerda e desvascularização da grande curvatura do estômago no tratamento da esquistossomose hepatoesplênica. É necessária a escleroterapia endoscópica pós-operatória? Arq Gastroenterol. 2001;38(2):84-8.

5. Brandt CT, Maciel DT, Caneca OA, Castro CM, Araújo LB. Autotransplant of spleen tissue in children with schistosomiasis: evaluation of splenic function after splenosis. Mem Inst Oswaldo Cruz. 2001;96 Suppl:117-22.

6. Kyaw MH, Holmes EM, Toolis F, Wayne B, Chalmers J, Jones IG, Campbell H. Evaluation of severe infection and survival after splenectomy. Am J Med. 2006;119(3):276. e1-7.

7. Brandt CT, Leite CRC, Castro RM, Brandt Filho C, Castro FMM, Castro CMMB. Aderência e atividade microbicida de monócitos em portadores de esquistossomose mansônica na forma hepatoesplênica cirúrgica. Acta Cir Bras. 2003;18(2):14353.

8. Brandt CT, Leite CRC, Castro RM, Brandt Filho C, Castro FMM, Castro CMMB. Avaliação do efeito da esplenectomia e auto-implante esplênico sobre algumas funções de monócitos em crianças com esquistossomose mansônica. Rev Soc Bras Med Trop. 2005;38(1):38-42. Epub 2005 Jan 18.

9. Brandt CT, Braga MVM, Melo KL, Pinho HS, Carvalheira R. Surgical hepatosplenic mansonic schistosomiais in adolescents: repercussions of the post-treatment schistosomotic burden on the hepatic functional reserve. Mem Inst Oswaldo Cruz. 2001;96 Suppl:113-5.

10. Shaheen AA, Abd el-Fattah AA, Ebeid FA. Effect of praziquantel treatment on lipid peroxide levels and superoxide dismutase activity in tissues of healthy and Schistosoma mansoni infected mice. Arzneimittelforschung. 1994;44(1):94-6.

11. Loverde PT. Do antioxidants play a role in schistosome hostparasite interactions? Parasitol Today. 1998;14(7):284-9.

12. Loverde PT, Carvalho-Queiroz C, Cook R. Vaccination with antioxidant enzymes confers protective immunity against challenge infection with Schistosoma mansoni. Mem Inst Oswaldo Cruz. 2004;9 (5 Suppl 1):37-43. Epub 2004 Oct 13.

13. Dzik JM. Molecules released by helminth parasites involved in host colonization. Acta Biochim Pol. 2006;53(1):33-64. Epub 2006 Jan 12.

14. Vertuani S, Angusti A, Manfredini S. The antioxidants and proantioxidants network: an overview. Curr Pharm Des. 2004;10(14):1677-94.

15. Salem TA, El-Refaei MF, Badra GA. Study of antioxidant enzymes level and phagocytic activity in chronic liver disease patients. Egypt J Immunol. 2003;10(1):37-45.

16. Thakur S, Gupta N, Kakkar P. Serum copper and zinc concentrations and their relation to superoxide dismutase in severe malnutrition. Eur J Pediatr. 2004:163(12):742-4.

17. Corbisier P, Houbion A, Remacle J. A new techinique for highly sensitive detection of superoxide dismutase activity by chemiluminescence. Anal Biochem. 1987;164(1):240-7.

18. Bergquist NR. Controlling schistosomiasis by vaccination: a realistic option? Parasitol Today. 1995;11(5):191-4.

19. Bergquist NR. Schistosomiasis: from risk assessment to control. Trends Parasitol. 2002;18(7):309-14

20. King CH, Dickman K, Tisch DJ. Reassessment of the cost of chronic helmintic infection: a meta-analysis of disabilityrelated outcomes in endemic schistosomiasis. Lancet. 2005;365(9470):1561-9.

21. Arita Y, Joseph A, Koo HC, Li Y, Palaia TA, Davis JM, Kazzaz JA. Superoxide dismutase moderates basal and induced bacterial adherence and interleukin- 8 expression in airway epithelial cells. Am J Physiol Lung Cell Mol Physiol. 2004;287(6):L1199-206. Epub 2004 Jul 30.

22. Goodall CP, Bender RC, Brooks JK, Bayne CJ. Biomphalaria glabrata cystosolic copper/zinc superoxide dismutase (SOD1) gene: association of SOD1 alleles with resistance/susceptibility to Schistosoma mansoni. Mol Biochem Parasitol. 2006;147(2):207-10. Epub 2006 Mar 9. 
Como citar este artigo:

Brandt CT, Leite CRC, Manhaes-de-Castro FM, Macedo EMC, Silva RPP, Castro CMM. Níveis de superóxido dismutase produzidos por monócitos em portadores de esquistossomose hepatoesplênica submetidos à esplenectomia, ligadura da veia gástrica esquerda e autoimplante de tecido esplênico no omento maior. Rev Col Bras Cir. [periódico na Internet] 2007;34(1). Disponível em URL: http: www.scielo.br/rcbc
Endereço para correspondência: Carlos Teixeira Brandt R. Boa Viagem, 5090 / 1201 51030-000 - Recife - PE 